\title{
Feminismo em tempos de tecnocegonha1: uma discussão acerca das novas tecnologias reprodutivas
}

\author{
Feminism in times of tecnocegonha ${ }^{2}$ : a discussion of new reproductive technologies \\ Tecnocegoña": una discusión sobre las nuevas tecnologías reproductivas \\ Karine de Andrade Torres ${ }^{3}$ \\ Karla Galvão Adrião ${ }^{4}$ \\ Universidade Federal de Pernambuco
}

\begin{abstract}
Resumo
As reflexões presentes neste artigo apresentam as discussões atuais tecidas pelos estudos feministas e de gênero no Brasil, acerca da temática das novas tecnologias reprodutivas (NTRs). As discussões realizadas apontam para aspectos relevantes acerca dos efeitos negativos que essas tecnologias geram no corpo da mulher, trazendo à tona a dominação dos corpos femininos e o reforço à naturalização. É importante dizer que não se pretendeu neste artigo negar os efeitos positivos das NTRs, mas sim, realizar uma problematização.

Palavras-chave: Feminismo; Gênero; Novas tecnologias reprodutivas.
\end{abstract}

\begin{abstract}
The reflections made present in this article shows the main discussions thought by feminist and gender studies in Brazil, especially focused on the theme of new reproductive technologies (NTRs). Those discussions point to relevant aspects about the negative effects cause by the same technologies in women's body, bringing light to domination of female bodies and enforcement to naturalization. It's important to say that this article does not intend to deny the positive effects of the NTRs, but stimulate a discussion.

Key-words: Feminism; Gender; New reproductive technologies.
\end{abstract}

\section{Resumen}

Las reflexiones presentadas en este artículo muestran los debates actuales llevados a cabo por los estudios de género sobre las mujeres en Brasil y sobre el tema de las nuevas tecnologías reproductivas (NTR). La discusión apunta para los aspectos relevantes sobre los efectos negativos que estas tecnologías generan en el cuerpo de la mujer, dejando al descubierto la dominación de los cuerpos de las mujeres y el fortalecimiento de la naturalización. Es importante decir que este artículo no está destinado a negar los efectos positivos de NTR, sino más bien realizar una problematización.

Palabras-clave: Feminismo; Género; Nuevas tecnologías reproductivas.

\section{Apresentação}

O objetivo deste artigo é refletir e apontar as principais discussões tecidas pelos estudos feministas e de gênero no Brasil acerca da temática das novas tecnologias reprodutivas (NTRs). O termo "Tecnologias Reprodutivas" necessita ser explicado neste artigo, uma vez que, em diversos trabalhos

1 Este termo, fictício, se refere a uma forma dotada de humor para relacionar a cegonha, animal que permeia o imaginário das crianças como forma de trazer os bebês ao mundo, com a tecnologia. Tem-se, então, um neologismo capaz de abarcar as relações entre as novas tecnologias e a questão do consumo e da construção dos corpos na contemporaneidade.

2 The term, fictitious, refers to a humor based figure, relating the cegonha (stork), which is commonly used to explain the children about the birth of a new baby, with technology. There is, then, a neologism that could encompass the relationship between new technologies and the issue of consumption and the construction of bodies in modern times.

Endereço 3: Av. Prof. Moraes Rêgo, 1235, Cidade Universitária, Recife - PE. CEP: 50670-901. Telefone para contato: (081) 21268000

Endereço 4: Av. Prof. Moraes Rêgo, 1235, Cidade Universitária, Recife - PE. CEP: 50670-901. Telefone para contato: (081) 21268000 acadêmicos seu uso torna-se, por vezes, confuso. Esta denominação, ou conceito, é bastante amplo, visto que abrange tanto as tecnologias contraceptivas - aquelas que evitam a gravidez, como as conceptivas - que dizem respeito aos métodos e procedimentos utilizados para a concepção, ou seja, para que a fecundação ocorra. Um outro debate acerca dessa expressão, diz respeito à palavra "novas". De acordo com o Dossiê de Reprodução Humana Assistida(2003)1, uma das hipóteses para esse adjetivo diz respeito ao fato de o processo de fecundação humana ter saído do corpo feminino e se transformado em objeto de manipulação laboratorial, ter se constituído em um evento extracorpóreo (in vitro).

Partiu-se do pressuposto de que, o acelerado desenvolvimento das tecnologias aplicadas ao campo

$1 \mathrm{O}$ dossiê foi publicado pela Revista Rede Feminista de Saúde - Rede Nacional Feminista de Saúde, Direitos Sexuais e Direitos Reprodutivos, Belo Horizonte, no ano de 2003, com apoio da Fundação Ford e colaboração de Marilena Corrêa, Médica, professora-adjunta do Departamento de Políticas e Instituições de Saúde do Instituto de Medicina Social da UERJ e pesquisadora visitante da Escola Nacional de Saúde Pública da Fundação Oswaldo Cruz; doutora em saúde coletiva (Ciências Humanas e Saúde) pelo IMS/UERJ 
da ciência contemporânea, em especial o surgimento das novas tecnologias reprodutivas, tem conduzido a uma série de transformações. Estas mudanças perpassam o âmbito familiar, sexual e das relações sexo/gênero, gerando novas formas de parentesco. Este trabalho busca discutir sobre o estado da arte nesse campo. Para dar início a este debate, entretanto, propromos discutir introdutoriamente os conceitos de família e de desejo por filhos, como forma de fortalecer o debate sobre as NTRs no debate feminista e de gênero.

\section{A família frente às Novas Tecnologias Reprodutivas}

Estudar a família, contemporaneamente, só é possível se pluralizarmos o termo e falarmos em famílias. Sabemos que o modelo de família nuclear em que pai, mãe e filhos moravam juntos, sob a proteção financeira do pai e emocional da mãe, não existe com a mesma frequência de apenas algumas décadas atrás ${ }^{2}$. E, se considerarmos que este modelo ainda existe fortemente, não pode ser tomado como referência única, tendo em vista as várias configurações familiares hoje existentes, como por exemplo: as famílias monoparentais, recasadas, unipessoais, etc ${ }^{3}$.

Se nos debruçarmos sobre o assunto em busca dos fatores que contribuíram para que toda essa mudança se processasse, vamos nos deparar com uma gama de elementos em que se destacam, entre outros, o surgimento da pílula anticoncepcional, a legalização do divórcio, os recasamentos, a aceitação do casamento homo-afetivo por diversos países, a entrada da mulher no mercado de trabalho e, em especial, os "avanços" 4 da ciência no sentido da criação das várias técnicas de reprodução humana.

Todas essas transformações acabaram por repercutir de modo especial sobre a mulher e sobre o lugar por ela ocupado na família e na sociedade em geral. A este respeito o movimento feminista ${ }^{5}$ tem muito a dizer e a contribuir. Autores como Hall (1988) e Boaventura de Sousa Santos (2000) vão tratar da importância do feminismo para o descentramento do sujeito moderno e da própria noção de ciência como

2 Somado a isso, temos o auxílio dos estudos de gênero, que vem problematizar estes lugares \posições de sujeitos cristalizados, particularmente na perspectiva pós-estrutural (Butler, 2003; Haraway, 2007).

3 Aliado a estes termos temos o debate em torno da circulação de crianças, trazido por Cláudia Fonseca (2004), segundo a qual, o cuidado das crianças nas comunidades populares pode passar por distintas e diversas pessoas, o que vem fortalecer a descaracterização de um modelo de família nuclear.

4 Aspeamos o termo avanço no sentido de problematizar os discursos e lugares da ciência na conformação dos corpos.

Trataremos destas questões mais adiante.

5 Utilizamos movimento feminista no singular para efeitos de escrita, embora tenhamos consciência da pluralidade interna aos movimentos. Nos filiamos a perspectiva pós-estrutural e a ela recorrremos ao longo do texto. lócus da verdade única. Estes impulsos reverberaram nas ações cotidianas de homens e mulheres, com atravessamentos de raça, classe, dentre outros. As mulheres de camadas médias ampliaram seu campo de ação e passaram a agir de maneira ativa no mercado de trabalho; porém, toda essa expansão não se deu sem que um alto preço precisasse ser pago. As cobranças sobre elas se multiplicaram. Algumas mulheres, além de esposas e mães, passaram a assumir o lugar de profissional, de preferência do tipo competente e respeitado. De acordo com Mansur (2003), além de cumprir as tarefas de antes, a mulher tornou-se também uma das principais fontes de renda e ganhou autoridade - passou de dona de casa à dona $d a$ casa $^{6}$.

Se até meados do século passado as posições de sujeito eram cristalizadas em lugares específicos destinados a cada sexo - reduzidos e delimitados -, limitando-se a mulher a cuidar da casa, dos filhos e do marido e o homem a prover a casa e sustentar a família, isso já não acontece de forma tão linear. Hoje, tanto a mulher quanto o homem de camadas médias urbanas acumulam, em sua maioria, funções sem uma divisão clara do que é típico de um e do outro. Neste sentido, prioridades se deslocam. Tanto a estabilidade econômica, quanto a profissional, assumem lugar prioritário. Sob esta ótica, torna-se fundamental qualificar-se, encontrar um bom emprego (e, se possível, estável) para, consequentemente, ser cogitada a ideia de constituir uma família. A procrastinação, se assim podemos chamar, da gravidez, é uma realidade. Segundo Collucci (2000, p.63) apud Borlot e Trindade (2004):

[...] a gravidez após os trinta e cinco anos cresceu na última década oitenta e quatro por cento nos Estados Unidos. A autora aponta que, no Brasil, apesar de existirem poucas estatísticas sobre o assunto, esta tendência tem sido confirmada (Collucci, 2000, p.63).

Apesar de a maternidade estar sendo adiada, sabemos que há um tempo determinado para a reprodução, principalmente no corpo das mulheres. Este sofre transformações, passando com ele também aquele momento em que seu organismo se prepara para melhor receber um bebê. Como bem apontam Gomes, Donelli, Piccinini e Lopes (2008), dentre os fatores negativos de uma gestação após os 35 anos são: elevado nível de ansiedade materna, maior incidência de abortos, hipertensão, hemorragias, partos prematuros, dentre outros ${ }^{7}$.

Tendo em vista as diversas exigências que lhe são feitas atualmente, a mulher de camadas médias urbanas, acaba por retardar a maternidade, e o desejo

6 Não discutiremos aqui a importância do debate de classe na reflexão sobre quem cuida da casa e do lugar das empregadas domésticas como cuidadoras, embora tenhamos consciência da importância dessa questão para o debate mais amplo.

7 Entretanto, outros autores relativizam estas questões, mostrando que, apesar da dita janela biológica, muitas mulheres, principalmente de camadas médias e altas, vem desenvolvendo a gestação após a idade de 35 anos, com tranquilidade. 
de se tornar mãe vem sendo colocado em segundo plano, fato acentuado nos últimos cinquenta anos. Desse modo, quando o casal sente a necessidade de ter um filho, pode ser tarde demais, já que o relógio biológico da mulher pode não mais atender aos anseios em prol da maternidade.

Diante de tudo isso, a procura pela Reprodução Assistida (RA), cada vez mais utilizada, torna-se, muitas vezes, a única alternativa que resta à mulher para gerar um bebê. De acordo com Freitas, Siqueira e Segre (2008), a reprodução humana assistida é, basicamente, a intervenção do homem no processo de procriação natural, com o objetivo de possibilitar que pessoas com problemas de infertilidade e esterilidade satisfaçam o desejo de alcançar a maternidade ${ }^{8}$.

Pesquisas recentes mostram que a cidade do Recife se posiciona como o maior pólo do Nordeste e um dos cinco do país no domínio desta técnica. Em matéria publicada no jornal Diário de Pernambuco, em 16 de Novembro de 2008, Neiva, (O sobrenome da jornalista é Neiva, seu primeiro nome é Ana, já consta nas referências no final do artigo) jornalista que assinou a matéria, afirma que o número de reproduções assistidas realizadas na cidade triplicou de 2003 para cá. De acordo com a matéria, são realizadas, em média, 900 gestações por meio desta técnica durante o ano.

Além do desejo de se ter um filho gerado pelo próprio ventre, a grande procura pela técnica também pode ser aliada ao seu custo. Há alguns anos atrás, a técnica de reprodução assistida era bem mais cara do que é hoje. Estima-se que o valor para a sua realização com sucesso encontra-se em torno dos 11 mil reais, quando realizada em clínicas particulares, o que, para uma parcela de casais, se torna insignificante diante do sonho de exercer a maternidade e a paternidade.

De acordo com uma matéria publicada no Jornal Diário de Pernambuco, no dia 26 de maio de 2009, Pernambuco ganhou o primeiro centro de reprodução humana do Norte e Nordeste totalmente custeado pelo Sistema Único de Saúde (SUS $)^{9}$. O serviço está funcionando no Instituto de Medicina Integrada Professor Fernando Figueira (Imip), no Recife. O programa vai atender também casais sorodiscordantes ${ }^{10}$. Nesses casos, o trabalho será evitar que o bebê ou um dos parceiros seja infectado. A expectativa é que, em médio prazo, haja a possibilidade de formar um banco de sêmen para também possibilitar que casais homoafetivos possam gerar filhos.

Acreditamos ser relevante salientar a existência de inúmeras técnicas de reprodução assistida. Segundo o website do Centro de Reprodução Humana - CRH, dentre as principais técnicas está a inseminação intra-

8 Embora saibamos que em muitos casos o desejo de pessoas do mesmo sexo por ter filhos também pode ser satisfeito por esta via. 9 Fonte: IMIP - Instituto de Medicina Integrada Professor Fernando Figueira

10 Portadores de HIV, Hepatite B e C. útero. Este procedimento, de baixa complexidade, consiste basicamente em selecionar os melhores espermatozóides e introduzi-los no útero no momento próximo à ovulação. Antes da inseminação, a mulher recebe hormônios para aumentar a quantidade de óvulos em condições de fecundar. Para os casais que não se beneficiam da inseminação, há a técnica de fertilização in vitro (FIV) conhecida popularmente como "bebê de proveta".

Ainda de acordo com o website do Centro de Reprodução Humana - $\mathrm{CRH}$, esta é a técnica de reprodução assistida de maior uso mundialmente. De maneira simples, na fertilização "in vitro" a mulher utiliza medicamentos para produzir um maior número de óvulos, sendo que o controle do desenvolvimento destes é feito com exames de ultra-som. Pesquisas comprovam que a FIV resolve 99\% dos casos de infertilidade. Neste método, a fertilização acontece fora do corpo, no laboratório, sob a supervisão do especialista. Existem dois tipos de FIV: a clássica, e a ICSI (injeção intracitoplasmática de espermatozóides). Na clássica, os óvulos são colocados em ambiente propício e inseminados com um número predeterminado de espermatozóides, proporcionando a fecundação de forma espontânea. Na ICSI, os óvulos são inseminados com o auxílio de um microscópio, que permite a colocação de um único espermatozóide no interior do óvulo. Esta técnica oferece maiores chances de ocorrer a fecundação. Diante de tudo isso, podemos perceber uma mudança bastante significativa na forma de conceber um filho. Segundo Ramírez-Gálvez:

$\mathrm{O}$ que antes era narrado como um ato privado, de intimidade e segredo, torna-se um ato público, um procedimento médico, assepticamente orientado e controlado, mediado por trocas econômicas. As crianças da RA são geradas sem sexo, num lugar especializado e distante do espaço íntimo e reservado dos pais. A história da cegonha deixou de ser ficção, tornou-se realidade (Ramírez-Gálvez, 2006, p.32).

Além deste fator, entra em jogo a frustração diante da tentativa sem sucesso e o preconceito que o casal poderá enfrentar, uma vez que a infertilidade ainda é um tema tabu na sociedade contemporânea. Corrêa e Arán (2008) problematizam a questão da indefinição da infertilidade e o papel do chamado: desejo por filhos. Para estas pesquisadoras, esse desejo seria o motor do processo de reprodução assistida. De fato, na ausência desse desejo, ninguém é definido ou diagnosticado como infértil. Concordando com Corrêa e Arán, Strathern (1992) observa que, para haver satisfação nesse empreendimento, deve haver o desejo, uma vez que sua ausência seria uma afronta ao significado de sua satisfação.

\section{Filhos: desejo ou direito?}

Desejo. Alguns possuem o desejo de adquirir 
um carro do ano, um tênis de marca, por ascender profissionalmente, já outros têm o desejo de ter um filho, de exercer a maternidade e a paternidade. Talvez o/a leitor/a ache essa comparação absurda e equivocada, porém, questionamos: $\mathrm{O}$ que se deseja quando se deseja um filho? Ser aceito por uma sociedade que valoriza o modelo de família nuclear - pai, mãe e filhos biológicos? Não desnaturalizar o que historicamente foi naturalizado? Para alguns, esse desejo vem de "dentro", ele é considerado natural, para outros, ele é construído socialmente, somos moldados e desejamos aquilo que nos convém desejar. ${ }^{11}$ Maier, em seu livro intitulado "Sem filhos: 40 razões para você não ter", aponta, de forma sarcástica, porém realista, motivos para não se ter filhos. Segundo Maier (2008), o desejo por crianças é tamanho que elas se tornaram um negócio dos mais rentáveis e em forte ascensão. Óvulos, esperma e bebês são vendidos diariamente no mundo inteiro e úteros são alugados por noves meses. As clínicas especializadas crescem constantemente. Nesse sentido, a autora acrescenta:

A ideia de crianças para todos e a qualquer preço gerou uma quantidade de discursos vulgares e caricaturais. Escolha um campo camarada; nunca se tem certeza do pior, mas na idiotice, sim. $\mathrm{Na}$ mão esquerda, tenho o fabuloso "direito ao filho". Reivindicação sagrada, podia-se quase esperar que estivesse inscrita no preâmbulo da Constituição. $\mathrm{O}$ filho é algo tão indispensável e maravilhoso que todo mundo deveria ter "direito" a isso. Quando virá o "direito inverso" à criança? (...) o filho não é um direito nem uma necessidade. Ele é simplesmente... uma possibilidade (MAIER, 2008, p. 24).

Diante do que foi exposto, o que é o direito ao filho? E quem o tem? Corrêa (2003), diz que questões diversas podem ser levantadas em relação à forma de encarar o desejo de ter filhos. Dentre elas, ressalta-se a ação médica presente nas tecnologias reprodutivas conceptivas, apresentadas hoje como a forma mais eficaz de realizar o desejo das pessoas impossibilitadas de se reproduzir, pelas mais diversas razões (p.31). A autora ressalta que, quando o desejo por filhos e o acesso às tecnologias reprodutivas conceptivas passam a ser encarados como um direito reprodutivo, é preciso problematizar e debater acerca de tais argumentos.

Nascimento (2009) problematiza a questão do acesso a essas tecnologias de ponta nos serviços de saúde pública e discute sobre como a instalação desses serviços pode configurar e redimensionar a questão do desejo por filhos e destaca a emergência de uma política pública nesse campo. Ainda segundo o autor, o discurso de popularização da reprodução assistida poderia estar ao mesmo tempo instituindo e alimentando esse desejo, de formas mais ou menos diretas (p.11). Sobre esse assunto, Menegon e Spink,

11 Não podemos nos furtar ao fato de que este desejo está inserido numa perspectiva macro estrutural, dentro de uma sociedade de consumo e capitalista o que também coloca o desejo nos termos de "valor de consumo" e de acesso a bens de consumo. colocam que:

Viabilizar esses desejos e ter acesso a eles por meio da reprodução humana assistida, além da complexidade técnica e psicossocial, estão diretamente relacionados às legislações e políticas públicas de cada país, que, por sua vez, dependem de padrões éticos locais e globais e de fatores econômicos, pois, fora o reduzido número de serviços públicos, os planos de saúde não cobrem esse tipo de assistência (2006, p.166).

Diante do exposto, vemos o caráter de desigualdade no que diz respeito ao acesso a essas tecnologias reprodutivas conceptivas. Aqueles que possuem maiores condições, não medem esforços para pagar o tratamento em clínicas privadas e ir a busca do tão sonhado "tecnofilho"12. Em contrapartida, aqueles que não tem condições de "bancar" esse tratamento, possuem duas opções: vender os seus bens para pagar a fertilização, ou esperar por atendimento nos serviços públicos de saúde.

Para Scavone (2006), as novas tecnologias reprodutivas colocam as mulheres em duas posições distintas. Se antes elas recorriam às tecnologias contraceptivas, decidindo pela não maternidade, agora recorreriam às tecnologias conceptivas, submetendose aos procedimentos técnicos do filho "a qualquer preço" e do "próprio sangue". Scavone acrescenta:

Esse desejo a qualquer preço da maternidade pode estar associado ao desejo da paternidade, cuja realização afirma a fecundidade e exalta a virilidade, especialmente em regiões onde o machismo é acentuado. Em pesquisas sobre maternidade, tem-se verificado que as mulheres referem-se, frequentemente, ao forte desejo de "dar um filho para o seu homem". Esse desejo seria mais forte do que seu próprio desejo de maternidade? (Scavone, 2006, p.16).

A questão da paternidade precisa ser debatida com mais frequência quando falamos em novas tecnologias reprodutivas, uma vez que, como dito anteriormente, a literatura tem privilegiado a descrição do impacto emocional da infertilidade e da experiência da reprodução assistida, principalmente nas mulheres. Além desse fator, o homem vem sendo colocado como coadjuvante nesse processo, como aquele que apenas apóia a sua parceira e que só é solicitado na hora de aportar o sêmen, adquirindo, dessa forma, um lugar passivo diante de seus desejos, medos e perspectivas.

Uma pesquisa realizada por Trindade e Enumo (2001) acerca das representações sociais da infertilidade feminina entre mulheres casadas e solteiras do estado do Espírito Santo, revelou que 12 Nos apropriamos da Expressão utilizada por Martha Ramírez - Galvéz (2006), quando a mesma reflete sobre a mercantilização do parentesco, que se dá através da possibilidade de selecionar e programar a carga genética dos bebês. A autora ressalta que deteç̧ão de doenças genéticas potenciais no embrião tem gerado negócios lucrativos. Nos Estados Unidos, a escolha de gametas por catálogo e de mães substitutas, divulgada amplamente pela internet, é promovida por instituições burocratizadas que envolvem intermediários, complexos contratos e remuneração, similar à intermediação para recrutar doadoras de óvulos. 
as mulheres de diferentes idades e níveis sociais, desejam e encaram a maternidade como uma mudança qualitativa em suas vidas. Por isso, quando vivenciam a impossibilidade da maternidade por vias naturais, ficam abaladas emocionalmente, se sentem estigmatizadas e lutam, a todo custo, pelo direito de ser mãe. A pesquisa revelou também que a maioria das mulheres entrevistadas acredita que a infertilidade não é problema para os homens e os classificaram como insensíveis, egoístas e irresponsáveis. As adjetivações utilizadas revelam o vigor do modelo tradicional de paternidade, espelhando a convivência com um pai nominal, distante dos cuidados e das preocupações próprias das relações parentais. Não obstante todos os elementos citados, nos deparamos com a ausência histórica dos homens no espaço reprodutivo, independente de ser no campo da R.A e, infelizmente, ainda hoje, a sociedade e a mídia focalizam o assunto da reprodução como predominantemente feminino. Quase nunca se pergunta ao homem sobre sua participação e desejo no processo de reprodução. Diante de tudo isso, torna-se preocupante o fato de termos poucos estudos abordando esses aspectos e por isso, destacamos a necessidade de refletirmos e problematizarmos sobre essas e outras questões no que diz respeito à paternidade no contexto das NTRs.

\section{Feminismo, gênero e novas tecnologias reprodutivas}

A relação do movimento feminista com a ciência e, em especial, com as novas tecnologias reprodutivas, tem sido um tema bastante discutido em congressos e encontros científicos ${ }^{13}$. Como comentado inicialmente, $\mathrm{o}$ artigo pretende abordar os principais momentos do debate feminista brasileiro na sua relação com as NTRs, no sentido de problematizar o desejo por filhos tratado nos tópicos anteriores.

De acordo com Corrêa e Arán (2008), o termo tecnologia remete a um ofício, à arte de fabricar, a um instrumento supostamente usado pelo homem para dominar a natureza. Para as autoras, esse termo reitera os dualismos presentes no pensamento moderno ocidental, como por exemplo: natural/ artificial, organismo/máquina, masculino e feminino. Essas categorias e dualismos acabam por associar o feminino à natureza e o masculino à cultura. Scavone (2006) traz alguns questionamentos acerca dessa discussão: as tecnologias de reprodução teriam rompido com o dualismo mulher/ natureza x homem/ cultura ou teriam acentuado? Se elas refletem o avanço da ciência e, portanto, um estágio do capitalismo, a 13 "Seminário Latino- Americano Feminismo e Novas Tecnologias Reprodutivas", realizado em Recife, em julho de 2006. "Jornadas Novas Tecnologias Reprodutivas Conceptivas: Questões e Desafios" realizadas pelo Núcleo de Identidades de Gênero e Subjetividades (NIGS), da Universidade Federal de Santa Catarina (UFSC), em Florianópolis, 2003. sua utilização poderia provocar conflitos e acelerar mudanças nas relações sociais e de gênero?

Segundo Laqueur (2001), durante muito tempo a mulher foi considerada inferior ao homem. Na Idade Média, tinha-se como referência o modelo de sexo único de Galeno, onde a mulher era considerada uma versão imperfeita do homem, uma vez que possuía o cérebro menor e órgãos sexuais internos e invertidos. Essa explicação foi usada por muitos anos para justificar o lugar inferior da mulher na sociedade. $\mathrm{Na}$ idade moderna, surge o modelo dos dois sexos, em que cada corpo apresentava, enfim, suas diferenças. Nogueira (2001) apud Nuernberg (2005) coloca que foi a partir da constatação científica de igualdade das capacidades intelectuais entre homens e mulheres que se passou a buscar na identificação dos temperamentos masculinos e femininos formas de associar a afetividade e docilidade às mulheres e a agressividade aos homens, legitimando, assim, duas formas de ser e agir conforme o sexo biológico.

Diante do exposto, é necessário situar o/a leitor/a acerca das categorias sexo/gênero, que segundo Butler (2008), foram pontos de partida para pensar uma política feminista. De acordo com Nicholson (2000), o termo "gênero" pode ser usado de duas maneiras diferentes: a primeira delas, em oposição ao termo "sexo", e se opondo ao que seria biologicamente dado, descreveria aquilo que é socialmente construído. A outra maneira é quando falamos de construções sociais que diferenciam "masculino" e "feminino". Butler (2008) critica a questão da criação do sexo como uma "norma" que diferencia e que dita o modo como os corpos devem moldar-se e apresentar-se. Nesse sentido, pensarmos em "corpos feminimos" e " corpos masculinos" dissociados de uma interpretação social torna-se impossível e por essa razão, pensarmos "sexo" independente de " gênero" também.

Butler (2008, p. 25) diz que, talvez, o próprio construto chamado "sexo" seja tão culturalmente construído quanto o gênero; a rigor, talvez, o sexo sempre tenha sido o gênero, de tal forma que distinção entre sexo e gênero revela-se absolutamente nenhuma. A autora reconhece a concepção de que o gênero não está para cultura como o sexo para a natureza.

Segundo Heilborn (1998), as propriedades simbólicas particulares à constituição do masculino e do feminino são fenômenos da relação hierárquica entre eles. Não podemos negar as diferenças existentes entre homens e mulheres, porém, devemos estar atentos ao valor que atribuímos a elas, pois é isso que permite estabelecer as relações de desigualdade.

Todas essas questões nos fazem refletir acerca da importância e da perspectiva que o movimento feminista contemporâneo traz ao debate. Rotania (2006) define o feminismo como:

(...) pensamento e ação política em um campo de incontestável riqueza teórica e prática. Nasce como uma ética visceral singular, pois revê e questiona 
os conceitos e os valores que historicamente têm levado a ignorar as mulheres como sujeitos éticos e políticos plenos. Propõe a mudança das relações de poder hierárquicas entre homens e mulheres, a conquista dos direitos civis, políticos e sociais e o exercício da autonomia plena em todos os domínios da vida social e pessoal (Rotania, 2006, p.40).

Segundo Scavone (2006), foi o movimento feminista que proporcionou uma maior visibilidade ao corpo e à sexualidade, tratando-os como questões políticas.

Nesse momento histórico (1960-1970), surgia também a pílula contraceptiva, possibilitando às mulheres decidir se queriam ou não ter filhos e qual o momento mais adequado. Desse ponto de vista, Scavone diz que as tecnologias conceptivas foram bem-vindas, pois estariam contribuindo para romper com o assujeitamento do corpo das mulheres, especialmente no que se referia à maternidade. Bassanezi (1997) coloca que, até metade do século XX:

A vocação para a maternidade e a vida doméstica seriam marcas da feminilidade, enquanto iniciativa, a participação no mercado de trabalho, a força e o espírito de aventura definiriam a masculinidade. A mulher que não seguisse seus caminhos, estaria indo contra a natureza, não poderia realmente ser feliz ou fazer com que outras pessoas fossem felizes (Bassanezi, 1997, p.609).

Simone de Beauvoir (1980), escritora, filósofa existencialista e feminista francesa, que se tornou referência clássica para pensar a mulher nas sociedades ocidentais, publicou uma das obras mais significativas para o debate sobre as vicissitudes da condição feminina. A obra intitulada: "O segundo sexo: fatos e mitos" promoveu a desconstrução dessas representações, até então vigentes. Beauvoir foi uma das primeiras mulheres a afirmar que não existe "instinto materno". Tal condição foi imposta à mulher e assumida como algo de "sua natureza".

Assumindo um salto histórico, chegamos ao final do século XX e início do século XXI, a partir do que argumenta Haraway, (De acordo com as referências são três autores - não está de acordo com as normas da revista - falta colocar os outros dois) (Questão resolvida nas referências - citada de forma adequada) filósofa, bióloga e feminista. Para ela não existe nada no fato de ser "mulher" que naturalmente una as mulheres. Não existe nem mesmo uma tal situação "ser mulher". Essa classificação, ou categoria, é muito complexa, tendo sido construída a partir de discursos científicos sexuais e outras práticas sociais, que a própria autora considera questionáveis. Concordando com Haraway (2009), Butler (2003) aponta a falsa estabilidade da categoria "mulher" e propõe buscar um modo de interrogação da constituição do sujeito que não requeira uma identificação normativa com o "sexo" binário.
Scavone (2006, p. 14) diz que, uma das idéias básicas do feminismo, no seu momento inaugural, foi expressa na máxima "nosso corpo nos pertence", na qual o corpo aparecia como um dos elementos centrais das relações de poder entre os sexos, nos espaços público e privado. Diante disso, vemos um discurso feminista abrindo possibilidades para um debate político sobre os corpos, afirmando suas diferenças e desigualdades construídas a partir das mesmas, discursivamente.

Retomando nossa idéia principal, o primeiro momento do feminismo com as novas tecnologias reprodutivas foi de certa forma positivo. Ainda não existiam críticas a essas tecnologias, pois se acreditava que elas viriam como uma solução para a libertação das mulheres em relação à maternidade. As tecnologias reprodutivas, seriam, dessa forma, usadas em benefício das mulheres. Além disso, segundo Scavone (2006), se a pílula contraceptiva havia dissociado a sexualidade da reprodução, as tecnologias conceptivas provocariam a ruptura definitiva.

O segundo momento do feminismo com as NTRs começou no final de 1970 e durou aproximadamente até o começo dos anos 1990 e já apontava críticas a essas tecnologias. Algumas críticas estão relacionadas à saúde, tanto das mulheres que se submetem ao procedimento, quanto dos bebês. Outro ponto criticado pelas feministas diz respeito ao fato de que a maior parte dos procedimentos são realizados no corpo da mulher. Ou seja, essas técnicas trariam à tona a questão da dominação dos corpos femininos e o reforço à naturalização que demarca desigualdades de gênero. Além disso, esses estudos trazem o argumento de que essas tecnologias surgem para, mais uma vez, reafirmar que o modelo aceito pela sociedade é o modelo de família nuclear, pai - mãe - filhos biológicos. Segundo Silva e Lopes (2008), (referências nas normas da APA) ao se instituir o modelo de família tradicional como "normal" ou "natural", há a reafirmação das dominações de gênero e, dessa forma, acaba-se por instituir uma forma padrão, um modelo de família e exclui as demais formas, tornando-as secundárias, inferiores e ilegítimas.

Ainda de acordo com Scavone (2006), nos anos 1980-1990 havia consenso na crítica feminista às novas tecnologias conceptivas. Tais críticas abarcavam questões como a crise do humano e o retorno à naturalização da maternidade. No entanto, os debates do feminismo pós - moderno trazem novos elementos para a discussão.

\section{Algumas reflexões finais}

Com este artigo propusemos trazer as discussões atuais tecidas pelos estudos feministas e de gênero no Brasil, acerca da temática das NTRs. Percebemos a 
complexidade da temática e a necessidade de mais debates, com o objetivo de levantarmos os desafios e conseqüências do uso dessas novas tecnologias. A esse respeito, Haraway (2009), (Questão já resolvida - verificar nas referências) traz significativas contribuições ao pensar nas novas tecnologias reprodutivas como produtos da era ciborgue que estamos vivenciando. A autora denomina o ciborgue como um organismo cibernético, um híbrido de máquina e organismo, uma criatura de realidade social e ficção (p. 36). A era do ciborgue é o aqui e o agora, onde quer que haja um carro, um telefone ou um gravador de vídeo. Somos todos ciborgues! Estamos envoltos em tecnologias de última geração em todas as esferas da nossa vida, desde um simples suco industrializado, até próteses mecânicas para braços e pernas que se movimentam de acordo com as informações que o nosso cérebro transmite. Nesse sentido, quando falamos em tecnologias de reprodução não podemos mais falar em oposições ou categorias como distintas e separáveis. No mundo tecnológico elas se misturam, não há separação entre público e privado, homens e mulheres, natureza e cultura, entre os humanos e as máquinas. De certa forma isso nos parece perigoso, na medida em que não podemos entender essa tecnologia como neutra, é importante sabermos quem é fruto de quem, que subjetividades essas novas tecnologias produzem e quais seus efeitos.

No campo das NTRs esta problematização é importante por colocar o debate em suas distintas nuances, além de situar o quanto o debate científico é permeado por políticas que formam e conformam corpos, subjetividades e desejos. A preocupação em se estas NTRs surgem para auxiliar o desejo de mulheres e homens em terem filhos ou se vem aprisionar desejos, corpos e subjetividades, recolocando as desigualdades de gênero em outras circunstâncias contínuas. Ou seja, será que o palco e as cenas mudam, com a inclusão das NTRs, possibilitando brechas nos modelos tradicionais e desiguais, ou permanecemos reafirmando dicotomias da ordem do sexo $\backslash$ gênero?

\section{Referências}

BASSANEZI, C. (1997). Mulheres dos Anos Dourados. In: História das mulheres no Brasil. Del Priore, M. (Org). São Paulo: Contexto.

BEAUVOIR, S. O Segundo sexo - fatos e mitos; tradução de Sérgio Milliet. 4 ed.São Paulo: Difusão Européia do Livro, 1980.

BORLOT, A. M. M..; \& TRINDADE, Z. A. (2004). As tecnologias de reprodução assistida e as representações sociais de filho biológico. Estud. psicol. (Natal), Natal, v. 9, n. 1.

BUTLER, J. (2008) Problemas de Gênero: feminismo e subversão da identidade. 2 ed. Rio de Janeiro: Civilização Brasileira.

CORRÊA, M. (2003) Medicina Reprodutiva e Desejo por filhos. In: Novas tecnologias reprodutivas conceptivas: questões e desafios. Miriam Pillar Grossi, Rozeli Maria Porto, Marlene Tamanini (Orgs.). Brasília: Letras Livres.
CORRÊA, M.; \& ARÁN, M. (2008). Tecnologia e normas de gênero: contribuições para o debate da bioética feminista. Revista Bioética. 16 (2): pp.191-206.

FREITAS, M; SIQUEIRA, A \& SEGRE, C. (2008). Avanços em reprodução assistida. Revista Brasileira de Crescimento e Desenvolvimento Humano, São Paulo, v. 18, n. 1, pp. 93-97, abr.

GOMES, A G.; DONELli, T. M. S.; PICCININI, C. A.; \& LOPES, R. (2008). Maternidade em idade avançada: Aspectos teóricos e empíricos. Interações em Psicologia, v. 12, pp. 99-106.

HARAWAY, D (2009). Manifesto ciborgue: ciência, tecnologia e feminismo-socialista no final do século XX. In: HARAWAY, D; HARI, K.; \& TOMAZ, T. Antropologia do ciborgue: as vertigens do pós - humano. Belo Horizonte: Autentica Editora.

HALL, S. (1988). A identidade na Pós-modernidade. Rio de Janeiro. DP\&A

HEILBORN, M. L. (1988). Gênero: um olhar estruturalista. In: PEDRO, Joana M. ET alli. Masculino, feminino, plural. Florianópolis, Ed Mulheres.

LAQUEUR, T. (2001). Inventando o sexo: corpo e gênero dos gregos à Freud. Rio de Janeiro: Relume Dumará.

MAIER, C. (2008). Sem filhos: 40 razões para você não ter. Rio de Janeiro: Intrínseca.

MANSUR, L. H. B. (2003) Sem filhos: a mulher singular no plural. São Paulo: Casa do Psicólogo.

MENEGON, V.; \& SPINK, M. J. (2006). Novas tecnologias reprodutivas conceptivas: problematizando a comunicação sobre riscos. In: FERREIRA, V.; ÁVILA, M. B.; PORTELLA, A. P. (Org.). Feminismo e novas tecnologias reprodutivas. Recife: SOS Corpo, p. 163-188.

NASCIMENTO, P. F. G. (2009). Reprodução, desigualdades e políticas públicas de saúde: uma etnografia da construção do "desejo de filhos". Rio Grande do Sul: Universidade Federal do Rio Grande do Sul, 2009, 213p. Tese (Doutorado). Programa de Pós-graduação em Antropologia Social. Porto Alegre.

NEIVA, A. (2009) Baby boom da fertilização. Recuperado em 19 de março, 2014, de http://www.diariodepernambuco.com. br/2008/11/16/urbana8_0.asp

NICHOLSON, L. (2000). "Interpretando o gênero". Revista Estudos Feministas, v. 8, n. 2, pp. 9-41.

NOGUEIRA. C. (2001). A análise do Discurso. Métodos e técnicas de avaliação: novos contributos para a prática $e$ investigação. Braga: CEEP.

RAMÍREZ-GÁLVEZ, M. C. (2006). A fertilização tecnológica dos nossos corpos. In: Feminismo e Novas Tecnologias Reprodutivas. Verônica Ferreira, Maria Betânia Ávila, Ana Paula Portella (Orgs.). Recife: SOS corpo - Instituto Feminista para a democracia.

REPRODUÇÃO ASSISTIDA PARA MÃES DO SUS. (2009). Diário de Pernambuco.com. br, Recife, 26 mai. Caderno vida urbana. Recuperado em 19 de março, 2014 de http://www.old. diariodepernambuco.com.br/nota.asp?materia=20090526064954

ROTANIA, A. A celebração do temor: biotecnologias, reprodução, ética e feminismo. Rio de Janeiro: E-papers, 2001.

SOUSA SANTOS, B. de. Pela mão de Alice: o social e o político na pós-modernidade. São Paulo: Cortez, 2000.

SILVA, N.R; \& LOPES, M.de F. (2008). A paternidade e a filiação afetiva nas técnicas de reprodução assistida heteróloga. Fazendo Gênero 8 - Corpo, Violência e Poder. Recuperado em 19 de março, 2014, de http://www.fazendogenero8.ufsc.br/sts/ST21/ Silva-Lopes_21.pdf

STRATHERN, M. (1992) Reproduction the future. Essays of antropology, kinship and the new reprodutctive technologies. Manchester, Manchester University Press.

SCAVONE, L. (2006). Novas Tecnologias Conceptivas: teorias e políticas feministas. In: Feminismo e Novas Tecnologias Reprodutivas. Verônica Ferreira, Maria Betânia Ávila, Ana Paula Portella (Orgs.). Recife: SOS corpo - Instituto Feminista para a democracia.

TRINDADE, Z. A.. ; \& ENUMO, S. R. F. (2001). Representações sociais de infertilidade feminina entre mulheres casadas e solteiras. Psicologia, saúde \& doenças. Espirito Santo, v.2, n. 2, pp. 5-26. 


\section{Sobre os autores:}

Karine de Andrade Torres - Mestra em Psicologia da Universidade Federal de Pernambuco.

E-mail: karinetorres@hotmail.com

Karla Galvão Adrião - Professora Adjunta da Universidade Federal de Pernambuco.

E-mail:kgalvaoadriao@hotmail.com 